\title{
A SAÚDE MENTAL DOS ESTUDANTES DA UFT - CÂMPUS DE MIRACEMA: SOBRE A MUDANÇA DAS NORMAS DE VIDA NO INÍCIO DA VIDA UNIVERSITÁRIA
}

Mental health of uft students - campus of Miracema: on changing life standards at the beginning of university life

Salud mental de los estudiantes de UFTT - campus de Miracema: sobre los cambios en los estándares de vida al comienzo de la vida universitária

\author{
Daniel Berg de Melo Farias ${ }^{1}$, José Fernando Patiño Torres ${ }^{2}$ \\ ${ }^{1}$ Curso de Psicologia, Universidade Federal do Tocantins, Miracema do Tocantins, Brasil. \\ 2 \\ Curso de Psicologia, Universidade Federal do Tocantins, Miracema do Tocantins, Brasil.
}

*Correspondência: Laboratório de Ciências, Instituto de Ensino Superior, Av. NS 15, 109 Norte, Palmas, Tocantins, Brasil.CEP:77.010-090.e-mailartigo@artigo.com.

Artigo recebido em 13/03/2020 aprovado em 06/11/2020 publicado em 01/12/2020.

\section{RESUMO}

O presente artigo é fruto de um trabalho o qual foi realizado com o apoio da UFT (Universidade Federal do Tocantins) e partiu de uma metodologia de investigação qualitativa a respeito das mudanças das normas de vida dos acadêmicos dos quatro cursos presentes no câmpus de Miracema. Como ferramentas para a coleta dos dados foram realizados grupos focais e entrevistas semiestruturadas. Entendendo por norma de vida uma regularidade individual a partir da perspectiva de Georges Canguilhem, foi possível evidenciar as principais dificuldades dos estudantes em construir ajustes diante das mudanças que surgiram/surgem ao ingressar ao mundo acadêmico. Entre as principais queixas, encontram-se as diversas responsabilidades em lidar com realidades da vida adulta nunca antes experimentadas, além das cobranças do meio acadêmico de forma explicita e implícita. Além disso, as reclamações diante das normas institucionais também se caracterizaram como um dos fatores de grande influência na dificuldade em se manter saudável, entendendo como saúde a capacidade de se reajustar às mudanças de normatividade. Através das discussões levantadas, foi possível perceber que a compreensão das decorrentes diferentes normas de vidas, as quais são inerentes da formação acadêmica, são complexas, no entanto, conhecer e entender as principais mudanças que afetam os demais universitários durante esse período é de suma importância para o âmbito social no qual nos encontramos.

Palavras-chave: Normas de vida; saúde, universidade.

\section{ABSTRACT}

This article is the result of a work which was carried out with the support of UFT (Federal University of Tocantins) and started from a qualitative research methodology regarding the changes in the standards of life of the academics of the four courses present at the Miracema campus. As tools for data collection, focus groups and semi-structured interviews were conducted. Understanding by life rule an individual regularity from the perspective of Georges Canguilhem, it was possible to highlight the main difficulties of students in building adjustments in the face of the changes that arose / arise when they enter the academic world. Among the main complaints, there are the various responsibilities in dealing with realities of adult life never experienced before, in addition to the demands of the academic environment in an explicit and implicit way. In addition, complaints regarding institutional norms were also characterized as one of the factors of great influence on the difficulty in staying healthy, understanding health as the ability to readjust to changes in regulations. Through the discussions raised, it was possible to realize that the understanding of the resulting different life norms, which are inherent to academic training, are complex, however, knowing and understanding the main changes that affect other university students during this period is of paramount importance. for the social environment in which we find ourselves.

Keywords: Norms of life; health, university. 


\section{RESUMEN}

Este artículo es el resultado de un trabajo que se realizó con el apoyo de la UFT (Universidad Federal de Tocantins) y comenzó a partir de una metodología de investigación cualitativa con respecto a los cambios en los estándares de vida de los académicos de los cuatro cursos presentes en el campus de Miracema. Como herramientas para la recolección de datos, se realizaron grupos focales y entrevistas semiestructuradas. Entendiendo por la regla de la vida una regularidad individual desde la perspectiva de Georges Canguilhem, fue posible resaltar las principales dificultades de los estudiantes para construir ajustes frente a los cambios que surgieron / surgieron cuando ingresaron al mundo académico. Entre las principales quejas, se encuentran las diversas responsabilidades en el manejo de realidades de la vida adulta nunca antes experimentadas, además de las demandas del entorno académico de manera explícita e implícita. Además, las quejas con respecto a las normas institucionales también se caracterizaron como uno de los factores de gran influencia en la dificultad para mantenerse saludable, entendiendo la salud como la capacidad de reajustar los cambios en las regulaciones. A través de las discusiones planteadas, fue posible darse cuenta de que la comprensión de las diferentes normas de vida resultantes, que son inherentes a la formación académica, son complejas, sin embargo, conocer y comprender los principales cambios que afectan a otros estudiantes universitarios durante este período es de suma importancia. por el entorno social en el que nos encontramos.

Descriptores: Normas de vida; salud, universidad.

\section{INTRODUÇÃO}

O presente projeto tem sido desenvolvido a partir de uma primeira imersão e vivência na Universidade Federal do Tocantins - Câmpus Miracema. É importante iniciar esclarecendo que as formas de lidar e conceber a organização educativa, suas estratégias, discursos e práticas de ensino e de avaliação nos cursos universitários, especialmente as inter-relações, tem consequências importantes não só para aprender conteúdos em determinadas disciplinas, mas, para além disso, na formação, na permanência na universidade, sobretudo, nas novas formas e ajustes de vida diante das mudanças que esse novo mundo instiga.

A inserção no ensino superior, de modo generalista, normalmente é vista como um elemento potencializador da mobilidade social e da possibilidade de realização de aspirações sobre o futuro, estejam estas vinculadas ao âmbito profissional ou pessoal. Todavia, estar na graduação pode possuir diversos sentidos, visto que este é um processo que envolve não só a utilização de funções intelectuais, como também abrange a complexa articulação entre processos emocionais e simbólicos do estudante. Para González Rey (2008), as emoções que o estudante vai desenvolver em sua trajetória universitária são tributárias não somente das experiências implicadas na sua formação acadêmica, como também englobam emoções oriundas de uma produção subjetiva de outros espaços da vida do discente (apud Bezerra, 2016).

Desse modo, esse campo a qual a presente pesquisa foi realizada, a universidade, além de se configurar como um espaço objetivo que envolve aspectos físicos, estruturais, naturais e geográficos, também se constitui em um espaço social, o qual se estrutura a partir das produções subjetivas. Assim, considerando que o espaço físico só tem significância quando referenciado pelo espaço social (Ewald, Gonçalves e Bravo, 2008), compreende-se que estar na graduação pode possuir diversos sentidos à medida que tal processo transcende a inserção no espaço institucional e se compreende envolta de aspectos simbólicos e emocionais compartilhados pela dimensão social, que serão responsáveis por atribuir novos sentidos às vivências aí experienciadas, assim como novas formas de ajustar aspectos da vida pessoal 
diante delas, criando uma nova normalidade individual.

Canguilhem (1996) aborda o conceito de normalidade diante da individualidade de cada sujeito, como algo único a cada ser, onde o homem cria sua própria forma de ver, sentir e estar no mundo. Ele chama essa normalidade individual de normatividade, entendendo, então, que possuímos normas de vida, regularidades que se estabelece em relação com o mundo. Canguilhem (1996), em sua obra "O Normal e o Patológico", critica a forma como o mundo de conceitos objetivos ao qual pertencemos se apega a criar "normalidades" que sejam universais, assim, classificando e categorizando sujeitos em modos de viver positivos e negativos.

Em relação a uma medida considerada válida e desejável - e, portanto, em relação a uma norma - que há excesso ou falta. Definir o anormal por meio do que é de mais ou de menos é reconhecer o caráter normativo do estado dito normal. Esse estado normal ou fisiológico deixa de ser apenas uma disposição detectável e explicável como um fato para ser manifestação do apego a algum valor. (Canguilhem, 1996, p. 12).

Diante desse conceito de normalidade, para Canguilhem (1996), cada sujeito deve estabelecer sua própria normatividade para com o mundo, ou seja, criar seus próprios meios para se manter saldável. Não se trata aqui de uma dialética simples do sujeito com o seu meio cultural e social, mas em todo o âmbito psicossocial. Essa norma de vida, e sua capacidade em criar ajustes diante das mudanças, é o que vai definir o seu estado como saudável, pois é o homem que a sente, é o homem que atribui sentido ao que ele está experimentando, é o homem que, dentro dessa totalidade individual que nós somos, vai se sentir doente (Canguilhem, 1996). Então, a doença, para esse autor, é uma construção valorativa. É um conceito construído a partir de uma articulação de pensamento, articulação esta justificada por valores.
Desta forma, a doença sempre se apresenta de maneira qualitativa, sendo um estado individual impossível de ser comparado a outros. De acordo com isso, um aspecto da vida subjetiva só pode se tornar norma de acordo com uma decisão que vai se inserir em uma hierarquia de valores. Sendo assim, a norma não é natural, ela é produzida. A norma em relação a qual é possível caracterizar uma doença não é natural, mas construída de acordo com determinados valores.

Diante desse debate, Foucault (2001) aborda o fato de como cada instituição, com suas relações de poder, desejam estabelecer normas, as quais procuram se sustentar em um lugar de verdade absoluta. É nesse espaço como instituição que a universidade se encontra, e, como Foucault aborda, cria também seus próprios modos de funcionamento, suas verdades que se concretizam enquanto leis a serem seguidas, ignorando a norma individual. Assim, o sujeito recém chegado a esse "novo mundo" encontra-se frente a mudanças as quais não consegue estabelecer ajustes, gerando sofrimentos junto a incerteza do que o aguarda nessa trajetória enquanto acadêmico.

Logo, a universidade, além de ser uma produção subjetiva de seus atores, também permite novas produções a eles, o que a torna um complexo espaço de subjetivação e, por conseguinte, de potentes fontes para a produção de aspectos qualitativos essenciais para o percurso do estudante no ensino superior. A possibilidade do estudante produzir um roteiro diferenciado, em relação ao que aprende e vivencia durante a graduação, explicita a importância dos aspectos críticos, reflexivos e dialógicos, pois estes reverberam não apenas nos processos de aprendizagem, mas também nos relacionais, os quais serão sumamente significativos na construção da trajetória universitária do estudante (Bezerra, 2016).

Desse modo, para uma análise mais aprofundada dos fenômenos relacionados ao sujeito em uma trajetória universitária, faz-se necessário 
privilegiar os espaços em que se insere esse estudante, pois considerando tais espaços como estruturados socialmente, o que de fato está sendo estimado é a subjetividade dos sujeitos ocupantes deste, bem como todas as configurações e desdobramentos emergentes das relações nele estabelecidas. Partindo de tal perspectiva, ao estudar sobre universitários, deve-se concentrar não somente no acadêmico, mas em tudo aquilo que engloba esse processo, todos os sujeitos e dimensões, que fazem parte de sua trajetória, pois é ao dar relevância aos contextos, que se pode realmente compreender o universitário em sua complexidade.

\section{MATERIAIS E MÉTODOS}

A presente pesquisa foi feita a partir da coleta de dados de grupos focais e entrevistas semiestruturadas com acadêmicos dos cursos de Psicologia, Serviço Social, Pedagogia e Educação Física da Universidade Federal do Tocantins Câmpus de Miracema. Este estudo situa-se no paradigma de pesquisa proposto por Fernando González Rey $(2009 ; 2007 ; 1997)$ e conhecido como Epistemologia Qualitativa. Essa proposta epistemológica se constitui dos seguintes princípios:

- O caráter interpretativo e construtivo de conhecimento sobre realidade social e a subjetividade. - O quantitativo e o qualitativo articulados na dimensão metodológica, mas nesse projeto se fará ênfase sobre o qualitativo no processo de construção do conhecimento.

- A validade e confiabilidade, uma vez do positivismo, são substituídas pela congruência e continuidade. Isto significa que o processo criativo de ideias gerados na pesquisa retroalimenta de forma permanente $o$ processo interpretativo acerca dos objetivos da investigação.

- O estudo da subjetividade, como uma produção que entrelaça de forma complexa o social e o individual.
Esta visão permite-nos compreender o caráter paradoxal da dinâmica sujeito e sociedade.

Vale esclarecer que a Epistemologia Qualitativa, não pertence a nenhuma disciplina social, pois uma das suas principais características é a construção de redes de conhecimento transdisciplinares que buscam superar olhares endógenos sobre os acontecimentos psíquicos (Patiño \& Goulart, 2016).

\section{RESULTADOS E DISCUSSÃO}

Dentro dos resultados parciais, temos encontrado que a possível lacuna existente entre a oferta universitária como uma opção de vida pessoalprofissional e as realidades contemporâneas dos alunos, cria fraturas muitas vezes preocupantes, caracterizadas por elevadas taxas de evasão e de baixo desempenho acadêmico, baixos níveis de vínculo laboral e a sensação geral de que o ensino superior precisa ser problematizado para ganhar relevância e impacto social. Portanto, é necessário compreender os processos que vivem estudantes universitários.

Foi possível evidenciar que as mudanças às quais os acadêmicos mais se queixam como difíceis de se adequar são:

1. Lidar com as responsabilidades da vida adulta, tais como pagar contas, economizar dinheiro, responsabilidades que, antes da vida acadêmica não se preocupavam. "Meu pais pagavam tudo, eu nem sabia como funcionava isso" (Raquel, 18 anos);

2. Lidar com o ritmo acelerado da universidade. "Ao mesmo tempo que não há cobrança, por ser um ambiente mais livre, você pode criar seus horários, mas, mesmo assim, a gente se cobra pra chegar 
na hora, entregar os trabalhos em dia, ler os textos também" (Luiza, 22 anos);

3. Sentir-se só mesmo em um contexto com grande circulação e interação de pessoas, "Aqui eu me sinto só demais, lá [onde sua cidade de origem] eu tinha meus amigos, minha família, aqui parece que é mais dificil de se aproximar das pessoas" (Lucas, 19 anos).

Diante dessas queixas, Canguilhem (1996), aborda que uma norma pode ser inferior no momento em que o sujeito não consegue criar novos ajustes diante das mudanças recorrentes, assim, sua regularidade pode se tornar paralisante, prendendo o sujeito em uma normatividade anterior, causando a dificuldade em readequar suas normas. Esse fator foi muito presente durante as entrevistas, alguns acadêmicos alegaram que, mesmo depois de algum tempo na universidade, ainda não se sentem fazendo parte dessa rotina.

\section{"Ainda tenho muita saudade da minha antiga vida" (Luiza, 22 anos).}

Canguilhem (1996) aborda essa dificuldade em se ajustar como sendo um dos principais fatores na instauração de um estado adoecedor.

Portanto, devemos dizer que o estado patológico ou anormal não é consequência da ausência de qualquer norma. A doença é ainda uma norma de vida, mas uma norma inferior, no sentido que ao tolera nenhum desvio das condições em que é válida, por ser incapaz de se transforma em outra norma. $\mathrm{O}$ ser vivo doente está normalizado em condições bem definidas, e perdeu a capacidade normativa, a capacidade de instituir normas diferentes em condições diferentes. (Canguilhem, 1996, p. 122).
Como é a realidade da vida universitária no geral, muitos estudantes da Universidade Federal do Tocantins deixam suas casas para viver o sonho de realizar a graduação, tendo novas possibilidades e um projeto de vida para o futuro. Quando se deixa o núcleo familiar, muitos acadêmicos assumem responsabilidades que até então era de outra pessoa dentro da família, logo, não apenas as questões de tempo, atividades domésticas, se tornam aspectos dessa mudança, mas também outros fatores se alteram qualitativamente, exemplo disso, o apoio social e afetivo.

A universidade como um novo espaço social vivenciado pelos estudantes se torna uma possibilidade para o estabelecimento de laços sociais, pois existem aspectos que fortalecem essa necessidade, que de certa forma pode funcionar como uma importante aspecto que coaduna para o estabelecimentos de reajuste de normas de vida, o que fortalece a permanência dos estudantes. Os laços duradouros tendem a servir como um apoio em momentos de dificuldade e se tornam uma prática de mão dupla, pois, ao mesmo tempo em que o acadêmico se disponibiliza como uma forma de apoio, ele também percebe a mútua troca afetiva.

Brito \& Koller in Juliano \& Yunes (2014) consideram que o apoio social e afetivo fornecido por um uma rede relacional de indivíduos é mantido por laços afetivos e dependem das próprias percepções acerca do mundo social, das competências e recursos disponíveis para a proteção. $\mathrm{O}$ aspecto afetivo acrescentado ao apoio social desempenha uma importante perspectiva para a manutenção do vínculo que se estabelece a partir das relações sociais que fazem parte do dia a dia dos jovens.

"A amizade aqui pra mim dentro do curso foi o alicerce pra mim, e... continua. Aí eu sempre digo que as amizades construídas aqui fazem 
você ter forças pra continuar e não voltar pra minha cidade, não desistir".

"Geralmente, a gente tem aquela coisa de não falar com os pais o que a gente tá passando, então, os amigos fazem esse papel de meio que cuidador do que a gente tá sentindo. Esse sentimento de solidão na universidade é constante".

Pode-se perceber que o apoio social e afetivo dos amigos ganha, muitas vezes, um sentido de família, não comparando em termo de importância, mas que é um forte fator que auxilia no próprio desenvolvimento do acadêmico, quando de fato se estabelece um vínculo que ganha um sentido subjetivo e uma representação simbólica. Logo, mesmo passando por algumas situações, estes preferem não comunicar a família para não gerar "preocupação", nestes momentos os amigos são o que fornecem, de alguma forma, o meio para que uma determinada norma se reconfigure, se reajuste, gerando uma normatividade que impede que uma norma de vida anterior, por dificuldade de se manter diante a mudança de cenário a partir da inserção na vida universitária, gere sofrimentos, adoecendo o sujeito.

Diante dessas queixas e relatos, as normas institucionais também se mostraram como uma grande causadora nas dificuldades de estabelecer novos reajustes.

"Aqui a gente vê que é difícil se manter também, né? É muito difícil conseguir auxilio, meus pais me ajudam pouco, isso afeta o meu rendimento" (Carlos, 20 anos).

"Eu percebi que passo mais tempo na universidade do que em casa. A universidade não me cobra isso, mas eu sinto sempre que tô fazendo pouco" (Fernando, 22 anos).
Pare esse tipo de controle, Magali (2008), aborda Foucault para evidenciar como as instituições criam normas, mesmo que implícitas para criar suas próprias normas

A sociedade disciplinar é caracterizada por Foucault como aquela que exerce seu poder de maneira diluída, através de instrumentos simples de controle: o olhar hierárquico, que estabelece o grau de adequação individual ao esperado, classificando a anormalidade; o objetivo normalizador, que se utiliza de técnicas para a readaptação do indivíduo e uma prática de exame, om vias a fiscalizar o processo de normalização (Silva, 2008, p. $145)$.

A construção do ensino como um processo fundamental na graduação, vem atrelado a fatores institucionais e pessoais que fomentam espaço de debate e da produção do conhecimento na universidade, sendo assim torna se necessário entender como essas relações se configuram e como elas afetam a vida do acadêmico, nesta mútua troca estabelecida.

A este respeito, se na universidade, como campo permanente de pesquisa, nos atrevemos a desafiar e transcender nossas lógicas institucionais governadas por olhares exclusivos dos adultos, olhares disciplinares e com vistas à racionalização, para um diálogo que ponha em tensão as convergências, divergências, contradições e afinidades com os jovens, também podemos tecer o caminho para uma universidade contemporânea que permite a inovação, a inclusão cultural e a construção de trajetórias acadêmicas mais significativas e gratificantes para os jovens e professores. Nesse sentido, argumentamos que a universidade, com os seus diversos atores e práticas institucionais, tem a função principal de promover a criação de sujeitos críticos, muito mais do 
que reproduzir as configurações subjetivas de ordens pré-estabelecidas.

Abordar os jovens como categoria social, aspecto que não tem sido fortemente explorado pelas ciências sociais e humanas, permite evidenciar que esse grupo geracional ainda carece de uma plataforma investigativa e interpretativa abrangente. É relevante mencionar que, embora na revisão da literatura se encontrem fontes que descrevem, de modo geral, as culturas juvenis, pouco tem sido ainda produzido visando a geração de conhecimentos teóricos relevantes e contextualizados sobre a experiência da juventude atual em ambientes universitários contemporâneos.

Diante desta realidade, esse trabalho visa aprofundar na compreensão da vida dos jovens, para aprender mais sobre eles, sobre como eles chegam para a formação e vida na faculdade, como vivem o processo da aprendizagem e da formação e o que imaginam em direção ao futuro imediato, em termos de vínculos laborais e como suas normas são reconfiguradas em um novo momento de suas vidas.

\section{CONCLUSÃO}

$\mathrm{O}$ ingresso no ensino superior, não é um momento único, é algo contínuo que se diversifica tanto pelo aprendizado da sala de aula, como pelo contato com outros sujeitos, com diferentes perspectivas de vida. Para estudar trajetória universitária é necessário considerar que os sujeitos são constituídos historicamente, logo a família, os amigos o ensino médio, são fatores que podem influenciar todo esse processo que se consolida na graduação, tanto o desenvolvimento acadêmico, como as configurações subjetivas que surgem através do contato com outros sujeitos e uma nova realidade social.

Através das discussões levantadas, é possível perceber que a compreensão das decorrentes diferentes normas de vidas, as quais são inerentes da formação acadêmica, são complexas, no entanto, conhecer e entender as principais mudanças que afetam os demais universitários durante esse período é de suma importância para o âmbito social em que nos encontramos, tanto como estudantes - futuros profissionais - como para os que atuam nesse contexto, seja como discente ou colaborador de áreas afins.

Desta forma, foi possível concluir que a trajetória acadêmica, não depende inteiramente de condições físicas, financeiras, mas através de uma complexa relação que se estabelece tanto no nível individual, como exemplo, a produção de sentido, e também o meio social, através das possibilidades que este dispõe para a consolidação de vivências que possam gerar sentidos simbólicos emocionais. Evidenciou-se que as relações sociais se apresentam como um forte fator gerador potencialidades, e também como uma forma de apoio social e emocional, e fomenta processos que atinge em diferentes níveis na vida de um sujeito.

Mesmo o ensino superior se dando de uma forma objetiva, é importante considerar a subjetividade e a singularidade de cada sujeito, quando se pretende estudar o processo de ensinoaprendizagem e a consolidação da trajetória universitária. Logo o contato de subjetividades produzem novos sentidos, assim como é possível perceber novos reajustes a vida individual e coletiva, causando impactos na própria identidade dos sujeitos que partilham de tal experiência.

Tendo que se adaptar a novos conceitos, novas vivências e experiências, o jovem universitário tem o seu desenvolvimento atravessado por progressos e fracassos, que sem duvidas são peças fundamentais na sua história durante e depois da academia. Esses processos enfrentados por essa classe incontestavelmente merecem atenção e, além disso, 
cuidados a partir daqueles que compreendem, de forma teórica e prática, a fragilidade da saúde mental do jovem e as diversas mudanças dos cenários social e institucionais, os quais fabricam as mais distintas normas que afetam o campo individual do sujeito e sua normatividade singular.

\section{AGRADECIMENTO}

Agradecemos inicialmente a Universidade Federal do Tocantins pela oportunidade de realizar tal pesquisa, assim como o orientador desta pesquisa, Dr. José Fernando Patiño Torres, a oportunidade de estágio no Programa de Saúde Mental - Mais Vida, a toda a equipe do grupo de pesquisa Subjectivus Fernanda Reis, Katerine Soares, Marissa M. Monteiro e Wysney Rocha - que colaborou e acompanhou todo o processo da pesquisa.

Todos os autores declararam não haver qualquer potencial conflito de interesses referente a este artigo.

\section{REFERÊNCIAS}

BEZERRA, M. S. (2016). Subjetividade e aprendizagem. In D. M. Goulart, \&, R. Alcântara (Orgs.), Educação Escolar e Subjetividade: desafios contemporâneos (1a ed., Cap. 4, pp. 51-68). Brasil: Global South.

\section{CANGUILHEM, G. (1996). O normal e o patológico}

(5a ed.) (M. T. R. Barrocas \& L. C. F. B. Leite, Trads.). Rio de Janeiro: Forense.
EWALD, A. P., GONÇALVES, R. R. \& BRAVO, C. F. (2008). O espaço enquanto lugar da Subjetividade. Rev. Mal-Estar Subj., Fortaleza, v. 8, n. 3, p. 755777.

FOCAULT, M. (2001). Os anormais - Cursos do Collège de France 1974-75 (E. Brandão, Trad). São Paulo: Martins Fontes.

GONZÁLEZ, F.L. (1997). Epistemología cualitativa y subjetividad. La Habana, Editorial Pueblo y Educación.

GONZÁLEZ, F.L. (2007). Investigación cualitativa y subjetividad. México, McGraw-Hill.

GONZÁLEZ, F.L. (2009). Epistemología y ontología: un debate necesario para la psicología hoy. In: Diversitas: Perspectiva Psicológica. Vol. 5, No. 3, 205-224.

JULIANO, M. C. C., \& YUNES, M. A. M. (2014). Reflexões sobre rede de apoio social como mecanismo de proteção e promoção de resiliência. V. XVIII, n. 3, pp. 135-154. Julho-Setembro. São Paulo: Ambiente e Sociedade.

PATIÑO, J.F. E GOULART, D. (2016). Qualitative Epistemology: A scientific platform for the study of subjectivity from a cultural-historical approach. International Research in Early Childhood Education, 7(1), 161-181. 